\title{
Mano-Thermo-Sonication in Food Preservation
}

\author{
Rishi Kumar Puri, Garima Gandhi, C.G. Shashank* and Taruneet Kaur
}

NDRI, Karnal, Haryana-132001, India

*Corresponding author

\section{A B S T R A C T}

\begin{tabular}{|c|}
\hline Keywords \\
\hline $\begin{array}{l}\text { Manothermo } \\
\text { sonication, Food } \\
\text { preservation, } \\
\text { Preservation } \\
\text { techniques }\end{array}$ \\
\hline Article Info \\
\hline $\begin{array}{l}\text { Accepted: } \\
\text { 20 June } 2018 \\
\text { Available Online: } \\
\text { 10 July } 2018\end{array}$ \\
\hline
\end{tabular}

\begin{abstract}
Food preservation is a process by which food materials are prevented from getting spoilt in order to retain in their best desirable condition for a long period of time. A major key mechanism involving food preservation is destruction or inactivation of spoilage microorganisms and/or enzymes. There are different types of emerging food preservation techniques and mano-thermo-sonication is one among them. Mano-thermo-sonication (MTS) is a food preservation technology that efficiently combines the effects of pressure, heat and ultrasonic waves at an optimal level to reach the desired levels of food stability and safety while ensuring minimum negative effects on quality of food material. It is a developing technique proved for its antimicrobial action and enzyme inactivation preventing food spoilage without altering organoleptic properties of foods subjected to it. The following review encompasses the research based findings and facts that support manothermosonication (MTS) as a potential food preservation technique which overcomes the deleterious effects of severe heat preservation processes on food.
\end{abstract}

\section{Introduction}

"Food preservation includes the processing and handling of food materials to stop or slow down spoilage and thus allow for longer storage". It includes processing of food to prevent it from undergoing undesirable changes making it further shelf stable. Preservation usually involves preventing the growth of spoilage bacteria, yeasts, fungi and other micro-organisms as well as retarding the action of spoilage enzymes like lipases, proteases etc. Food preservation can also include processes which inhibit sensory deterioration that can occur during food preparation and/or storage. Traditional food preservation techniques are primarily based on reducing the free moisture content in food thereby dampening the biological processes. Some of these include drying, refrigeration, curing, smoking, pickling, sugaring etc. Pasteurization or heat treatment is the most widely used method of food preservation technique. Recent advancements in nonthermal technologies have shown potential as alternative to conventional heat treatment, being able to inactivate pathogens, spoilage microorganisms and enzymes without the adverse effects on food quality associated with thermal pasteurization. The major drawback of heat is its non-specificity in processing. Heat treatments while inactivating microorganisms 
can also modify the nutritional and sensory profile of foods in undesirable manner. Therefore, food industry is currently looking for alternative and more specific preservation techniques, which besides ensuring the stability and safety of foods, will not greatly modify their quality. During non-thermal processing, the temperature of foods is kept considerably less than the temperature employed in conventional thermal processing; therefore, least degradation of food quality is likely. However, non-thermal technologies must not only improve food stability but also augment safety levels, when compared with other procedures or techniques they replace. This approach has led to combining nonthermal methods of food preservation techniques with conventional or thermal processes which helps to reduce the severity of treatments needed to obtain a required level of safety. This combination can possibly augment the lethal potency of processing on microbes and/or prevent the proliferation of survivors following treatment. Manothermosonication is a combined preservation technique now gaining importance in food industry.

\section{Mano-thermo-sonication}

Manothermosonication (MTS) combines and synergises the ultrasound with moderate temperature and pressure in order to inactivate enzymes and/or micro-organisms. This technique has seen convincing developments in past three decades for food preservation owing to its ability to inactivate microorganisms and endogenous enzymes while retaining nutrients and flavour (Butzet al., 1995). Harvey and Loomis (1929) first documented the lethal effects of ultrasound on living organisms and since then, its use has been continuously recommended for disinfection and food preservation (Paci, 1953; Jacobs and Thornley, 1954; Boucher, 1980; Gaboriaud, 1984). Sound waves having frequencies $>20 \mathrm{kHz}$ are considered as ultrasounds and in context of food preservation, upper limit is usually taken to be $5 \mathrm{MHz}$ in gases and $500 \mathrm{MHz}$ in liquids and solids. The first studies on high hydrostatic pressure (HHP) preservation of foods were conducted in early 1890s(Hite, 1899).

It was demonstrated that microbial inactivation with ultrasound increases when treatment is applied under pressure (Manosonication, MS) (Raso et al., 1998b). The lethality of ultrasound under higher static pressure was reported to be remarkably greater within a given pressure range (0 to $300 \mathrm{kPa}$ ). The application of MS treatment simultaneously with heat (Manothermosonication) surges the microbial inactivation manifolds. A major advantage of using MTS is a higher extent of specificity as acoustic energy is absorbed specifically at the interface of membranes causing targeted heating (Floros and Liang, 1994). This heating effect has also assumed to be responsible for increasing the permeability of the living membranes resulting in complete loss of their selectivity. For instance, significantly increased rate of diffusion of sodium ions through living frog skin under ultrasound was demonstrated by Lehmann and Krusen (1954).

Since, MTS is undertaken at comparatively lower temperatures than conventional thermal processes, a product with heat sensitive components can be treated. The local molecular temperature, however, is rising during the treatment. Therefore careful temperature control is required. Also, the treatment time is actually longer during the destruction and/or inactivation of microorganisms and/or enzymes varying with product to product, which may cause highenergy requirement (Burgos, 1998). Thus, MTS is an emerging technology that efficiently exploits the effect of heat and ultrasonic waves synergised by pressure. 


\section{Mechanism}

In MTS, major role of micro-organism and enzyme inactivation is played by ultrasound and temperature while pressure acts as a synergising energy that helps to optimize the overall intensity of the process. Here we can consider the individual effect of pressure, ultrasound and heat in order to understand their combined outcome. Ultrasound is defined as sound waves with frequencies above that of human hearing (typically higher than $18 \mathrm{kHz}$ ). These waves can be propagated in liquid media as alternating compression. If ultrasound has sufficient energy, cavitation takes place in the medium. This phenomenon involves the formation, growth, and sudden collapse of microscopic bubbles. These collapsing bubbles deliver very high temperatures (approximately $5000 \mathrm{~K}$ ) and pressures (estimated at $50000 \mathrm{kPa}$ ) momentarily to the liquid media (Suslick 1988; Sala et al., 1995). High pressure results in physico-chemical changes, often leading to longer shelf life. High pressure destroys the cell membrane function, leading to cell leakage.

Thus, summing up the mechanism of MTS, the ultrasound generates the cavitation or bubble implosion in the media. These implosions can cause inactivation and/ordestruction of micro-organisms and enzymes. The simultaneous pressure treatment maximizes the intensity of the explosion, which results in greater levels of inactivation. The mechanism of microbial killing is mainly due to thinning of cell membranes, localized heating and production of free radicals (Piyasena et al., 2003). Very strong shaking of molecules takes place causing breakage of bonds. This result in liberation of dipicolinic acid and some low molecular weight polypeptides from the cortex of spores of certain bacterial species. Rehydration of the protoplast occurs resulting in loss of heat resistance. The loss in heat resistance at acidic $\mathrm{pH}$ of the medium is also caused by the rehydration of protoplast as a result of cortex degradation (protonization) (Leistner and Gorris, 1997).

Another observed peculiarity of MTS treatment in microbial and enzyme inactivation is that it is a bi-phasic process i.e. a faster rate of inactivation in initial stages of treatment followed by decrease in inactivation for remaining course of treatment (Lopez et al., 1994; Lee et al., 2009). Although it is an established fact that efficacy of MTS treatment increases with increase in temperature but after a certain temperature increase (boiling point of the medium), the lethality of MTS has been observed to decrease (Lopez and Burgos, 1995; Vercet et al., 1997; Kuldiloke, 2002). A possible reason for this weakened effect could be decreased intensity of bubble implosions because of elevation of the water vapour pressure inside the bubble with rise in temperature (Vercet et al., 1997). It has already been proved that the effect of heat and ultrasonic waves in enzyme inactivation combines synergistically. This is actually derived from the result that the inactivation rate of combined treatment is larger than the sum of the rate of inactivation by ultrasound at room temperature and the rate of inactivation by simple heating. Microbial and enzyme inactivation by MTS follows first order kinetics and there are a number of models developed by researchers (Lopez et al., 1994; Mañas et al., 2000; Chen and Hoover, 2004; Gómez et al., 2005 a, b; Álvarez et al., 2007) to predict the process requirements that could interest the industry.

\section{MTS in microbial inactivation}

The decimal reduction time (D value) of Yersinia enterocolitica has been reported to decrease eight times after mano-sonication treatment $(600 \mathrm{kPa}, 150 \mu \mathrm{m})$. It has been 
reported that MTS treatment reduced heat resistance of Staphylococcus aureus by 63 per cent (Ordoñez et al., 1987) and that of $B$. subtilis by 43 per cent (Garcia et al., 1989), as compared to their heat resistance at the same temperatures. Pagan et al., (1999) investigated the effect of MTS $\left(200 \mathrm{kPa}, 117 \mu \mathrm{m}, 62{ }^{\circ} \mathrm{C}\right.$ for 1.8 minutes) on heat-shocked and nonheat-shocked cells of Listeria monocytogenes and reported maximum levels of inactivation under MTS treatment as compared to thermally treated samples. Piyasena et al., (2003) reviewed the possibility of ultrasound in microbial inactivation and suggested manothermsonication to be most effective among non-thermal preservation techniques.

Lee et al., (2009) investigated the effect of MTS (20 kHz, $124 \mathrm{~mm}$ amplitude) at 40, 47, 54 , and $61{ }^{\circ} \mathrm{C}$ and $100,300,400$, and $500 \mathrm{kPa}$, on inactivation of $E$. coli in phosphate buffer (0.01 M, pH 7). They reported that the combination of lethal factors (heat, ultrasound and pressure) significantly shortened the exposure time necessary to attaina $5 \log$ reduction. Investigations on other spore forming bacteria (B. cereus, B. coagulans and $B$. stearothermophilus), non-spore forming bacteria (Aeromonas hydrophila) and yeasts (Saccharomyces cerevisiae) show that lethality of MTS treatment was greater (5 to 30 times) than that of the corresponding heat treatment at the same temperature (Raso and Barbosa-Canovas, 2003).

The lethal effects of MTS treatment has been found to be additive in case of vegetative cells but on the other hand, a synergistic effect has been observed in case of spore of Enterococcus faecium and B. subtilis (Raso et al., 1998c; Pagan et al., 1999). Also, there is a direct correlation between the rate of microbial inactivation to the amplitude of ultra-sound and pressure for all microorganisms (Pagan et al., 1999).
In order to optimize suitable MTS parameters with maximum $3 \log$ reduction of Listeria inocula in milk based smoothie, Palgan et al., (2012)conducted a study where, MTS (200 K $\mathrm{Pa}, 35^{\circ} \mathrm{C}$ ) treatment was varied at different levels of amplitude (50, 75, $100 \%)$ and residence time $(2.1,1,0.7 \mathrm{~min})$. It was reported that increase in residence time and amplitude significantly reduced the microbial count ( $p<0.001$ ) as compared to the untreated control samples. In an another study Guzel et al., (2014) evaluated the effect of MTS on inactivation of Listeria monocytogenes and Escherichia coli in acidic fruit juices like that of apple and orange. Variation in MTS (110 $\mu \mathrm{m}$ amplitude, and $200 \mathrm{KPa}$ pressure) was applied at different temperatures (50, 55, $60^{\circ} \mathrm{C}$ ). It was concluded that MTS could be a credible alternative to existing pasteurization treatments for fruit juices as the combination of ultrasound and heat treatment synergistically inactivated $L$. monocytogenes STCC 5672 and E. coli O157:H7.

Kahraman et al., (2017) reported the efficacy of MTS $\left(40,50,60^{\circ} \mathrm{C}\right.$ temperature and 100 , 200 , and $300 \mathrm{kPa}$, pressure) in reducing the $E$. coli $\mathrm{O} 157: \mathrm{H} 7$ population in apple-carrot juice to $5 \mathrm{log} \mathrm{CFU} / \mathrm{g}$ in comparatively shorter time as compared to that of traditional HTST treatment. Along with microbial parameters, MTS was reported to be able to mend the chemical parameters such as antioxidant activity and total phenolic content. It was also noted that increase in temperature not only reduced the microbial population, but also the time required to achieve the same.

Sour cherry juice was mano-thermosonicated at varying levels of amplitude (50, 75, 100\%) and temperatures $\left(20,30,40^{\circ} \mathrm{C}\right)$ at different time intervals $(2,6$, and $10 \mathrm{~min})$ at a constant frequency of $20 \mathrm{KHz}$ by Turken and Erge (2017). The results revealed the positive influence of MST on reduction of Escherichia coli $\mathrm{O} 157: \mathrm{H} 7$ by temperature and treatment 
time $(p<0.05)$ along with phenomenal increase in total monomeric anthocyannins and antioxidant capacity of juice. In an another study conducted by Zhu et al., (2017) on blueberry juice, it was reported that MTS $\left(560 \mathrm{~W}, 5 \mathrm{~min}, 40{ }^{\circ} \mathrm{C} / 350 \mathrm{MPa}, 40{ }^{\circ} \mathrm{C}\right.$ ) for 5 , $10,15,20$ minutes was highly significant in inactivating Escherichia coli O157:H7 and reducing their population by $5.85 \mathrm{log}$.

\section{MTS in enzyme inactivation}

MTS has been demonstrated to be very effective in inactivation of enzymes associated with food spoilage which otherwise endure the conventional thermal treatment. This method can significantly decrease the activity of many enzymes like pectin esterase (PE) enzyme of various fruit juices at the moderate pressure $(100-300 \mathrm{kPa})$ and temperature below $100^{\circ} \mathrm{C}$. Kuldiloke (2002) achieved almost complete inactivation of PE (94 per cent inactivation at $70^{\circ} \mathrm{C}, 300 \mathrm{kPa}, 2 \mathrm{~min}$ and 96 per cent inactivation at $80^{\circ} \mathrm{C}, 200 \mathrm{kPa}, 5 \mathrm{~min}$ ) and also reported that the efficacy of the process depended upon $\mathrm{pH}$, time of exposure, temperature, pressure and amplitude of the ultrasound

Effect of MTS treatment has been tested on food deterioration agents, enzymes and microorganisms mainly on model enzymes and microorganisms. For instance, enzyme inactivation efficacy of MTS treatment has been reported to be considerably greater than that of thermal processing at the same temperature. Some of such reports include greater inactivation levels of polyphenol oxidase (PPO), lipase and protease (Lopez et al., 1994; Vercet et al., 1995; Vercet et al., 1999), soybean lipoxygenase (Lopez and Burgos, 1995a), horseradish peroxidase (Lopez and Burgos, 1995b), tomato pectic enzymes (Lopez et al., 1998), orange pectin methylestrase (PME) (Vercet et al., 1999) and orange-carrot blend PME (Lyng et al., 2012).
PME is a pectic enzyme present in citrus fruit juices and is responsible for their quality deterioration by objectionable precipitation of cloud particles, thus deactivation of this enzyme is critically required during juice processing. MTS has been proved to be an efficient tool to inactivate other enzymes native to milk such as lipoxygenase, peroxidase and proteases and lipases from psychrotrophic bacteria (Lopez et al., 1994; Sala et al., 1995; Vercet at al., 1997). Lee et al., (2005) reported that application of heat $\left(72^{\circ} \mathrm{C}\right)$ and ultrasound $(20 \mathrm{kHz}, 117 \mu \mathrm{m})$ simultaneously under moderate pressure (200 $\mathrm{kPa}$ ) surged the inactivation rate of PME in orange juice by 25 times in buffer, and over 400 times in orange juice. A 10-fold decrease in lysozyme activity was achieved by MTS treatment $\left(117 \mu \mathrm{m}, 200 \mathrm{kPa}, 70{ }^{\circ} \mathrm{C}\right)$ for 3.5 min (Condon et al., 2006). Kuldiloke (2002) investigated the inactivation of PE by MTS in the pressure range 100 to $300 \mathrm{kPa}$ at temperature varying between 40 and $80^{\circ} \mathrm{C}$, and ultrasound $20 \mathrm{kHz}$. Treatment time was 5 minutes. Kuldiloke (2002) described the enzyme inactivation as a first order kinetic model.

Gamage et al., (2007) reported better enzyme inactivation in tomato juice treated with MTS (20 kHz, $2 \mathrm{~kg}$ pressure, $117 \mu \mathrm{m}$ amplitude at $70{ }^{\circ} \mathrm{C}$ forl $\mathrm{min}$ ) as compared to thermally treated (TT) samples. PME activity was found to fall by almost 38 per cent of the initial values in TT samples whereas in MTS-treated tomato juice it was undetected. Thermally treated tomato juice showed no decrease in polygalacturonase (PG) activity whereas MTS treated samples saw 62 per cent inactivation of total PG activity.

Maragoniet al., (1989) investigated the effect of MTS on POD isozymes in tomato and reported that heat and ultrasound play a synergistic role in inactivation of the enzymes and increasing either of the parameters results 
in synergistic increase in the process efficacy. Kuldiloke (2002) investigated the effect of MTS treatment on various food enzymes. He reported that the extent of inactivation by MTS increases with increase in temperature in the range of $40-80{ }^{\circ} \mathrm{C}$. Based on lower $D$ values and higher $z$-values of MTS treatment, Kuldiloke (2002) also indicated that MTS could inactivate lemon, tomato and strawberry $\mathrm{PE}$ at temperature where thermal inactivation was insignificant. This fact implies that MTS treatment is more efficient at temperature lower than the corresponding thermal treatment. Reason behind this could be the impairment of protection provided to the enzymes by food molecules.

\section{Effects on food material}

The application of ultrasonic waves generating cavitation in suspensions, containing enzymes and micro-organisms, has a lethal result and deactivating action (Suslick, 1988). High power ultrasound waves when propagate through a liquid, it causes the pre-existing and newly formed micro bubbles to vibrate at an identical frequency. Increasing acoustic pressure causes the growth and powerful collapse of these bubbles, which is accompanied by a sudden increase of the temperature and the pressure in small local surrounding area. Food preservation by elevated temperature for short period of time is still the most common form of food preservation process (Davies, 1959; Kinsloe et al., 1954; Pagan, 1997; Raso et al., 1998e). In most cases the controls and process variables are derived by first-hand analysis of the effect of time and temperature of exposure on microbial survival kinetics with lesser emphasis on quality of food in relation to effects of heat treatment on food composition and structure. The damage to food quality occurs due to modification of macromolecules, deformation of plant and animal structures and production of new substances from heat-catalyzed reactions. The non-covalent bonds in proteins, nucleic acids and carbohydrates undergo changes leading to different molecular structures.

Gamage et al., (2007) compared the physical properties of MTS $(20 \mathrm{kHz}, 2 \mathrm{~kg}$ pressure, 117 $\mu \mathrm{m}$ amplitude and $70{ }^{\circ} \mathrm{C}$ for $1 \mathrm{~min}$ ) and thermally treated tomato juice. They reported that the MTS treated samples were superior in terms of higher apparent viscosity (1.6 times) and yield stress values (2.2 times), better consistency (1.9 times higher) and lower flow index.

There have been a number of publications relating to the utility of ultra-sound in food industry. For example, ultra-sound treatment provides better emulsification properties (Mason et al., 1996); aids in better extraction (Stasiak, 2005; Chendke and Fogler, 1975), crystallization (Mason et al., 1996), dehydration (Ensminger, 1988) and freezing (Zheng and Sun, 2006). Dolatowski et al., (2007) has also reported ultra-sonication to improve tenderness of meat which is a highly desired property among consumers.

\section{MTS in dairy industry}

From review of literature, it is established that MTS treatment by virtue of its mechanism is best suited for acidic $\mathrm{pH}$ products. A few researchers have examined the possible uses of this technology in dairy products. Dolatowski et al., (2007) reported that the use of ultrasound as a processing aid can reduce the production time of yoghurt of up to 40 per cent. Lopez et al., (2002) claimed MTS (20 $\mathrm{kHz}$ ultrasound amplitude, $2 \mathrm{~kg}$ pressure, and $40{ }^{\circ} \mathrm{C}$ for $12 \mathrm{~s}$ ) as an effective tool for achieving better rheological and physical properties in yoghurt and also reported the treatment to attain a certain level of homogenization. 
Halpinet al., (2013) compared the microbial growth profile in raw milk treated with conventional thermal treatment $\left(72{ }^{\circ} \mathrm{C}, 20 \mathrm{~s}\right)$ and MTS (frequency; $20 \mathrm{kHz}$, amplitude; 27.9 $\mathrm{mm}$, pressure; $225 \mathrm{kPa}$ ) at two temperatures (37 and $55{ }^{\circ} \mathrm{C}$ )followed by pulsed electric field (electric field strength; $32 \mathrm{kV} / \mathrm{cm}$, pulse width; $10 \mu \mathrm{s}$, frequency; $320 \mathrm{~Hz}$ ). They reported significantly lower microbial counts in thermally treated samples than in MTS+PEF treated samples. A possible reason for this could be a higher $\mathrm{pH}$ conditions prevailing in raw milk as MTS is more effective in lower $\mathrm{pH}$ mediums. Condón et al., (2011) claimed to achieve a $99.99 \%$ inactivation of $C$. sakazakii cells (in milk) when treated with MTS $\left(35^{\circ} \mathrm{C} ; 200 \mathrm{kPa} ; 117\right.$ $\mu \mathrm{m}$ for $4 \mathrm{~min}$ ). They also reported that same level of inactivation could be reached within 1.8 minutes when the temperature is raised to $60{ }^{\circ} \mathrm{C}$.

In conclusion, three of the energies viz. heat, pressure and ultrasound have been known and tested for their individual ability to aid in food preservation. But, there are respective demerits of each technique such as higher power requirement, greater exposure time, food tissue damage, loss of nutrients, rheological changes, incompetence in safety etc. Combined processing with these energies has been researched and gained interest as hurdle technology in past three decades and proved to be very much promising in overcoming or minimizing the detrimental effects on food material while achieving better food safety and stability levels. A higher specificity of MTS is not only confined to micro-organisms and enzymes only, but to the whole cellular structure. Thus, this targeted treatment can be modified in such a way to yield the desired levels of food preservation or processing. MTS has shown to be potential food preservation and processing technique while exhibiting least negative effects on food material which qualifies it to advance from a lab scale technology to an industrial one. Nevertheless, the studies on food safety as well as the appropriate pre and post-treatment changes need to be investigated in detail.

\section{References}

Álvarez, I., Condón, S. and Raso, J. 2007. Microbial inactivation by pulsed electric fields. In: Raso. J. and V. Heinz, editors. Pulsed Electric Field Technology for the Food Industry, Springer Applied Science, N.Y. pp. 95-128.

Boucher, R. M. G. 1980. Process for ultrasonic pasteurization. 4,211,744 United States Patent.

Burgos, J. 1998. Minimal Methods of Processing- Manothermosonication, Academic Press, London 928p.

Butz, P., Funtenberger, S., Haberditzl, T. and Tauscher, B. 1995. High pressure inactivation of Byssochlamisnivea ascospores and other heat-resistant moulds. Lebensm-Wiss- Tecnol. 29: 404-410.

Chen, H. and Hoover, D. G. 2004. Use of Weibull model to describe and predict pressure inactivation of Listeria monocytogenes in whole milk. Innovative Food Sci. Emerging Technol. 5: 269-276.

Chendke, P. K. and Fogler, H. S. 1975. Macrosonics in industry. Part 4: Chemical processing Ultrasonics. 13(1):31-37.

Condon, S., Manas, P. and Cebrian, G. 2003. Nonthermal Preservation of Foods Using Combined Processing Techniques. Crit. Rev. Food Sci. Nutr. 43(3):265-285.

Condon, S., Manas, P. and Cebrian, G. 2011. Manothermosonication for microbial inactivation. In: Feng, H., BarbosaCanovas, G. V. and J. Weiss, editors. 
Ultrasound technologies for food and bioprocessing. Springer Science and Business Media, London, pp. 287-321. Davies, R. 1959. Observations of the use of ultrasound waves for the disruption of microorganisms.

Biochemica

BiophysicaActa. 33:481-493.

Dolatowski, Z. J., Stadnik, J. and Stasiak, D. 2007. Applications of ultrasound in food technology. Acta. Sci. Pol. Technol. Aliment. 6(3): 89-99.

Ensminger, D. 1988. Acoustic and electroacoustic methods of dewatering and drying. Drying Technol. 6(3): 473-499.

Floros, J. D. and Liang, H. 1994. Acoustically assisted diffusion through membranes and biomaterials: High-intensity ultrasound accelerates diffusion and can be used to improve food processes. Food Technol. 79p.

Gaboriaud, P.L.F. 1984. Sterilisation de liquides par ultrasons. French patent 2 $575641 \mathrm{~A} 1$.

Gamage, T.V., Wu, J., Vilkhu, K.S., Simons, L.K. and Mawson, R. 2008. Effect of thermosonication on quality improvement of tomato juice. Innovative Food Sci. and Emerging Technol. 9: 186-195.

Garcia, M.L., Burgos, J., Sanz, B. and Ordonez, J.A. 1989. Effect of heat and ultrasonic waves on the survival of two strains of Bacillus subtilis. J. Appl. Bact. 67: 619-628.

Gómez, N., García, D., Álvarez, I., Condón, S. and Raso, J. 2005a. Modeling inactivation of Listeria monocytogenes by pulsed electric fields. Int. J. Food Microbiol. 103: 199-206.

Gómez, N., García, D., Álvarez, I., Raso, J. and Condón, S. 2005b. A model describing the kinetics of inactivation of Lactobacillus plantarum in a buffer system of different $\mathrm{pH}$ and in orange and apple juice. J. Food Engng. 70: 7-
14.

Guzel, B.H., Arroyo, C., Condón, S., Pagán, R., Bayindirli, A. and Alpas, H. 2014. Inactivation of Listeria monocytogenes and Escherichia coli by ultrasonic waves under pressure at nonlethal (manosonication) and lethal temperatures (manothermosonication) in acidic fruit juices. Food bioprocess technol. 7(6):1701-1712.

Halpin, R.M., Cregenzán-Alberti, O., Whyte, P., Lyng, J.G. and Noci, F. 2013. Combined treatment with mild heat, manothermosonication and pulsed electric fields reduces microbial growth in milk. Food control. 34: 364371.

Harvey, E. and Loomis, A. 1929. The destruction of luminuous bacteria by high frequency soundwaves. J. Bact. 17: 373-379.

Hite, B.H. 1899. The effects of pressure in the preservation of milk. West Virginia Agric. Exp. Stat Bull. 58: 15-35.

Jacobs, S.E. and Thornley, M.J. 1954. The lethal action of ultrasonic waves on bacteria suspended in milk and other liquids. J. Appl. Bact. 17: 38-56.

Kahraman, O., Lee, H., Zhang, W. and Feng, H. 2017. Manothermosonication (MTS) treatment of apple-carrot juice blend for inactivation of Escherichia coli 0157: H7. Ultrasonicssonochemistry. 38, 820-828.

Kinsloe, H., Ackerman, E. and Reid, J.J. 1954. Exposure of microorganisms to measured soundfields. J. Bact. 68: 373-380.

Kuldiloke, J. 2002. Effect of ultrasound, temperature and pressure treatments on enzyme activity and quality indicators of fruit and vegetable juices. Dissertation. University of Berlin.

Lee, H., Zhou, B., Liang, W., Feng, H. and Martin, S.E. 2009. Inactivation of 
Escherichia coli cells with sonication, manosonication, thermosonication, and manothermosonication: microbial responses and kinetics modeling. $J$. Food Engg. 93: 354-364.

Lee, J.W., Feng, H. and Kushad, M. 2005. Effect of Manothermosonication (MTS) on Quality of Orange Juice. In: AIChE Annual Meeting, Conference Proceedings. 12272-75p.

Lehmann, J.F. and Krusen, F.H. 1954. Effect of pulsed and continuous application of ultrasound on transport of ions through biologic membranes. Arch. Phys. Med.Rehab. 35: 20-27.

Leistner, L. and Gorris, L.G.M. 1997. Food preservation by combined processes. Final Report FLAIR Concerted Action No. 7, Subgroup B (Internet Word 6.0 Version- 1997), European Union.

Lopez, P. and Burgos, J. 1995a. Lipoxygenase inactivation by manothermosonication: effects of sonication physical parameters, $\mathrm{pH}$, $\mathrm{KCl}$, sugars, glycerol and enzyme concentration. J. Agric. Food Chem. 43: 620-625.

Lopez, P. and Burgos, J. 1995b. Peroxidase stability and reactivation after heat treatment and manothermosonication. J. Food Sci.60(3): 451-455, 482.

Lopez, P., Sala, F. J., de la Fuente, J. L., Condon, S., Raso, J. and Burgos, J. 1994. Inactivation of peroxidase, lipoxygenase, and polyphenol oxidase by manothermosonication. J.Agri. Food Chem. 42: 252-256.

Lopez, P., Sanchez, A. C., Vercet, A. and Burgos, J. 1997. Thermal resistance of tomato polygalacturonase and pectinmethylesterase at physiological pH, Z. LebensmUntersForsch A. 204: $146 \mathrm{p}$.

Lopez, P., Vercet, A., Rosa, O., Marquina, P. and Crelier, S. 2002. Rheological Properties of Yoghurt Made with Milk
Submitted to Manothermosonication. Agric. Food Chem. 50: 6165-6171.

Lopez, P., Vercet, A., Sanchez, A.C. and Burgos, J. 1998. Inactivation of tomato pectic enzymes by manothermosonication. Zeitschrift fur Lebensmitteluntersuchung undForschung 207: 249-252.

Lyng, J.G., Caminiti, I.M., Noci, F., Morgan, D.J. and Cronin, D.A. 2012. The effect of pulsed electric fields, ultraviolet light or high intensity light pulses in combination with manothermosonication on selected physico-chemical and sensory attributes of an orange and carrot juice blend. Food and Bioproducts Processing. 90: 442-448.

Mañas, P., Pagán, R. and Raso, J. 2000. Predicting lethal effect of ultrasonic waves under pressure treatments on Listeria monocytogenes ATCC 15313 by power measurements. J. Food Sci. 65(4): 663-667.

Marangoni, A.G., Brown, E.D., Stanley, D.W. and Yada, R.Y. 1989. Tomato peroxidase: Rapid isolation and partial characterization. J. Food Sci. 54: 1269.

Mason, T.J., Paniwnyk, L. and Lorimer, J.P. 1996. The uses of ultrasound in food technology. Ultrasonics Sonochemistry. 3: 253-260.

Ordonez, J.A., Aguilera, M.A., Garcia, M.L. and Sanz, B. 1987. Effect of combined ultrasonic and heat treatment (thermoultrasonication) on the survival of a strain of Staphylococcus aureus. J. Dairy. Res. 54: 61-67.

Paci, C. 1953. L'emploi des ultra-sons pour l'assainissementdulait. Le Lait. 33: 610-615.

Pagan, R. 1997. Resistencia frente al calor y losultrasonidosbajopresión de Aeromonas hydrophila, Yersinia enterocoliticay Listeria 
monocytogenes. Ph.D. Thesis, University of Zaragoza.

Pagan, R., Manas, P., Raso, J. and Condon, S. 1999. Bacterial resistance to ultrasonic wavesunder pressure at non-lethal (manosonication) and lethal (manothermosonication) temperatures. Appl. Environ. Microbiol. 65: 297300.

Palgan, I., Muñoz, A., Noci, F., Whyte, P., Morgan, D.J., Cronin, D.A. and Lyng, J.G. 2012. Effectiveness of combined pulsed electric field (PEF) and manothermosonication (MTS) for the control of Listeria innocua in a smoothie type beverage. Food Control. 25(2):621-625.

Piyasena, P., Mohareb, E. and McKellar, R.C. 2003. Inactivation of microbes using ultrasound: a review. Int. J. Food Microbiol. 87: 207-216.

Raso, J. and Barbosa-Canovas, G.V. 2003. Non-thermal preservation of foods using combined processing techniques. Crit. Rev. Food Sci. Nutr. 43(3): 265-285.

Raso, J., Barbosa-Canovas, G. and Swanson, B.G. 1998a. Sporulation temperature affects initiation of germination and inactivation by high hydrostatic pressure of Bacillus cereus. J. Appl. Microbiol. 85:17-24.

Raso, J., Calderon, M.L., Gongora, M., Barbosa-Canovas, G.V. and Swanson, B.G. 1998b. Inactivation of Zygosaccharomyces bailiiin fruit juices by heat, high hydrostatic pressure and pulsed electric fields. $J$. FoodSci.63: 1042-1044.

Raso, J., Gongora-Nieto, M., BarbosaCanovas, G., and Swanson, B.G. 1998c. Influence of several environmental factors on the initiation of germination on Bacillus cereus by high hydrostatic pressure. Int. J.Food Microbiol.44:125-132.
Raso, J., Pagán, R., Condón, S. and Sala, F.J. 1998d. Influence of temperature and pressure on the lethality of ultrasound. Appl. Environ. Microbiol. 64:465471.

Raso, J., Palop, A., Pagan, R. and Condon, S. 1998e. Inactivation of Bacillus subtilis spores by combining ultrasonic waves under pressure and mild heat treatment. J. Appl. Microbiol. 85: 849-854.

Sala, F.J., Burgos, J., Condon, S., Lopez, P. and Raso, J. 1995. Effect of heat and ultrasound on micro-organisms and enzymes. In: Gould, G. W. (ed) New Methods of Food Preservation. London, Blackie Academic and Professional, pp. 176-204.

Stasiak, D. M. 2005. The ultrasound assisted sugar extraction from sugar beet cossettes. Acta. Sci. Pol. Techn. Agrar. 4 (2): 31-39.

Stead, D. 1986. Microbial lipases: their characteristics, role in food spoilage and industrial uses. J. Dairy Res. 53: 481.

Suslick, K. S. 1988. Homogeneous sonochemistry. In: Suslick, K. S. (ed.) Ultrasound. Its Chemical, Physical and Biological Effects, New York, NY, VCH, pp. 123-163.

Türken, T. and Erge, H.S. 2017. Effect of ultrasound on some chemical and microbiological properties of sour cherry juice by response surface methodology. Food Sci. Technol. Int. 23(6): 540-549.

Vercet, A., Lopez, P. and Burgos, J. 1995. Inactivation of heat-resistant lipase and protease from Pseudomonas fluorescens by manothermosonication. J. Dairy Sci. 27: 29-36.

Vercet, A., Lopez, P. and Burgos, J. 1997. Inactivation of heat-resistant lipase and protease from Pseudomonas fluorescens by manothermosonication. 
J. Dairy Sci. 80: 29.

Vercet, A., Lopez, P. and Burgos, J. 1999. Inactivation of heat-resistant pectinmethylesterase from orange by manothermosonication. J. Agric. Food Chem. 47: 432-437.

Zheng, L. and Sun, D. W. 2006. Innovative applications of power ultrasound during food freezing processes - a review. Trends Food Sci. Technol. 17:
16-23.

Zhu, J., Wang, Y., Li, X., Li, B., Liu, S., Chang, N., Jie, D., Ning, C., Gao, H. and Meng, X. 2017. Combined effect of ultrasound, heat, and pressure on Escherichia coli O157: H7, polyphenol oxidase activity, and anthocyanins in blueberry (Vaccinium corymbosum) juice. Ultrasonics sonochemistry. 37: 251-259.

\section{How to cite this article:}

Rishi Kumar Puri, Garima Gandhi, C.G. Shashank and Taruneet Kaur. 2018. Mano-ThermoSonication in Food Preservation. Int.J.Curr.Microbiol.App.Sci. 7(07): 2743-2753. doi: https://doi.org/10.20546/ijcmas.2018.707.321 